\title{
Incidence of cancer in first-degree relatives of basal cell carcinoma patients
}

\author{
M. M. van Rossum $\cdot$ D. Wopereis $\cdot$ T. Hoyer $\cdot$ I. Soerjomataram $\cdot$ J. Schalkwijk $\cdot$ \\ P. C. M. van de Kerkhof $\cdot$ L. A. L. M. Kiemeney $\cdot$ N. Hoogerbrugge
}

Received: 14 April 2008 / Revised: 8 August 2008 / Accepted: 3 October 2008 / Published online: 5 November 2008

(C) The Author(s) 2008. This article is published with open access at Springerlink.com

\begin{abstract}
There is evidence to suggest that genetic factors play an important role in the development of basal cell carcinomas (BCCs), and that skin neoplasms might be a sign for a genetic predisposition to cancer. We investigated whether the incidence of visceral and skin malignancies among first-degree relatives of BCC-patients was increased. Postal questionnaires were sent to 249 BCCpatients, who were divided into two groups (young = BCC under the age of 51 years and older $=\mathrm{BCC}$ over the age of 50 years), and asked them about cancer in their first-degree relatives. The reported numbers of cancer among the relatives were compared with the expected numbers based on sex and age-specific population-based incidence rates. The accuracy of the reported diagnoses was verified. A total of
\end{abstract}

M. M. van Rossum ( $($ ) · D. Wopereis · T. Hoyer · J. Schalkwijk ·

P. C. M. van de Kerkhof

Department of Dermatology,

Radboud University Nijmegen Medical Centre,

P.O. Box 9101, 6500 HB Nijmegen, The Netherlands

e-mail: m.vanrossum@derma.umcn.nl

I. Soerjomataram

Department of Public Health, Erasmus Medical Centre,

Rotterdam, The Netherlands

L. A. L. M. Kiemeney

Department of Epidemiology and Biostatistics and Department of Urology, Radboud University Nijmegen Medical Centre,

Nijmegen, The Netherlands

L. A. L. M. Kiemeney

Comprehensive Cancer Centre IKO, Nijmegen, The Netherlands

N. Hoogerbrugge

Departments of Clinical Genetics and Oncology,

Radboud University Nijmegen Medical Centre,

Nijmegen, The Netherlands
157 BCC-patients reported 277 malignancies in 1,272 relatives. The incidence of the following cancers was higher than expected in relatives from young BCC-patients: bone and soft tissue $(\mathrm{O} / \mathrm{E}=3.91 ; 95 \% \mathrm{CI}$ : $1.43-8.66)$, skin $(\mathrm{O} /$ $\mathrm{E}=2.13 ; 95 \%$ CI: $1.30-3.29)$ and digestive tract $(\mathrm{O} /$ $\mathrm{E}=1.59 ; 95 \% \mathrm{CI}: 1.10-2.23)$. In relatives of older BCCpatients, only the incidence of digestive tract cancer was higher than expected $(\mathrm{O} / \mathrm{E}=1.44 ; 95 \%$ CI: $1.08-1.89)$. Diagnoses that were verified turned out to be accurate in $87 \%$ of the cases. This study suggests that the risk of certain cancers, particularly that of the digestive tract, in firstdegree relatives of BCC-patients is increased. These findings may indicate a genetic predisposition to both skin and visceral malignancies in this patient group.

Keywords Basal cell carcinoma $\cdot \mathrm{BCC} \cdot$ Relatives . Genetics $\cdot$ Visceral malignancies

\section{Introduction}

Cutaneous malignancies are the most common type of cancer in the western world, with basal cell carcinomas (BCCs) accounting for about $75 \%$ of all skin cancers. The life-time risk for BCCs is about one in six [1]. Most BCCs have a superficial or nodular growth pattern and are classified as "non-aggressive", whereas only a minority of the tumours is associated with a considerable chance of local recurrence. Although mortality rates are low, BCCs may grow per continuitatem and cause severe local destruction. Metastasis occurs in less than $1 \%[19,22]$.

It is clear that the incidence of BCCs is increasing [5, 13]. Although most BCCs occur in older persons, the incidence in young patients is increasing disproportionately [3, 19]. BCCs occur most on sun-exposed areas of the body, 
such as the head and neck ( $80 \%$ of cases). Acute and chronic skin exposure to ultraviolet radiation is supposed to be a crucial factor in the development of skin cancer [9, 22]. However, it is not likely that the increased incidence in young persons over time is due to sun exposure alone. In a study by Lear et al. [11], outdoor occupation turned out not to be a risk factor, which implies that ultraviolet radiation cannot be the only explanation for the increased incidence of BCCs. Additionally, mutations in the hedgehog signalling pathway can be identified in almost all BCCs but less than $50 \%$ of these mutations have the typical UV signature $[1,9,19]$. Genetic factors might play a role in skin carcinogenesis as skin cancer among first and second degree relatives is associated with multiple BCCs [26]. A considerable part of the young patients has multiple BCCs and it was shown that DNA repair capacity in young BCC-patients without associated abnormalities is decreased [14]. Earlier studies reported on families with multiple BCCs without associated anomalies in subsequent generations and on patients with multiple unilateral BCCs [8].

It is known that skin disorders can form a first manifestation of a genetic predisposition to cancer: for example, patients with basal cell naevus syndrome (BCNS), which is caused by a germ line mutation in the PTCH1gene, have multiple BCCs at a young age, palmoplantar pits, bone abnormalities, odontogenic keratocysts and an increased risk of medulloblastomas and neoplasms of the ovaries [12]. Patients with DNA repair disorders also have an increased risk of developing non-melanoma skin cancer (NMSC): Muir Torre syndrome, a variant of the Lynch syndrome, is defined by the combined occurrence of at least one sebaceous gland neoplasm and a visceral malignancy. The sebaceous neoplasms in this syndrome include adenomas, epitheliomas and carcinomas. Besides, BCCs and keratoacanthomas can be found [4, 16, 24].

Patients who have BCC have an increased occurrence of second primary tumours of head and neck, bladder, larynx, lung and colon as well as non-Hodgkin's lymphoma and melanoma [11, 23, 27]. Besides, the incidence of second primary cancers of head and neck, thyroid, lung, larynx, bladder, colon, as well as cutaneous malignant melanoma, non-Hodgkin's lymphoma and leukemias are increased after NMSC appearance. Furthermore, earlier studies found that mortality from noncutaneous malignancies was 20 $30 \%$ greater when patients have had NMSC [18].

These data illustrate that skin disorders might function as a signal for a genetic predisposition to cancer. However, little is known about the cause and relevance of having BCCs at a young age and no data is available with regard to BCCs in relation to visceral (i.e. non-skin) malignancies. In this exploratory study, we hypothesise that BCCs indicate a genetic predisposition to cancer and investigated whether the incidence of visceral malignancies in first-degree relatives of BCC-patients is increased.

\section{Patients and methods}

After approval of the ethics committee was obtained, postal questionnaires were sent to BCC-patients who visited the outpatient clinic of the departments of Dermatology or Plastic surgery of the Radboud University Nijmegen Medical Centre between 1993 and $1998(n=340)$. All patients who could be traced $(n=249)$ were asked to complete the questionnaire. Patients who did not respond within 5 weeks received a reminder. Subsequently, all patients who did not fill out the questionnaire completely or did not respond were approached by telephone. Patients were asked about site and year of their first and subsequent BCCs and total number of BCCs. Furthermore, we asked year of birth and year of death of all their first-degree relatives (parents, children and siblings). We also asked for each relative whether that relative had ever been diagnosed with cancer, year of diagnosis and type of cancer. With respect to the first-degree relatives without cancer, we asked to fill out year of birth and, if applicable, year of decease. BCC-patients were divided into two groups: young patients who had their first BCC under the age of 51 years and older patients who had their first BCC over the age of 50 years. The cut-off point of 50 years to differentiate "young" and "old" BCC-patients is based on expert opinion which rests on the age distribution of BCCs that shows an increase from 50 years onwards and analogy with other cancers. For example, in colorectal carcinoma the cut-off point of 50 years is used to determine whether this cancer may be hereditary or not [25].

In order to determine the accuracy of the reported cancer diagnoses among relatives, we sent 124 BCC-patients, who reported cancer among their relatives, a letter and requested them to contact their relatives and ask them to give consent to confirm the diagnosis in the database from The Netherlands Cancer Registry (NCR). Two weeks later the BCCpatients received consent forms that they could send to their relatives. Whenever a relative had deceased, his/her children or wife/husband could give consent for confirmation of the diagnosis. When relatives did not respond within 2 weeks, we approached the BCC-patients by telephone and asked them whether their relatives were willing to participate. Reported diagnoses of cancer were compared with data from the NCR. When the diagnosis from the NCR differed from the reported diagnosis, we approached the relative by telephone to discuss this inconsistency.

The observed numbers of cancer were compared with the expected numbers based on the Dutch age and sex-specific population-based incidence rates (http://www.ikcnet.nl). 
Because The Netherlands has a nationwide populationbased cancer registry, reference values can be taken efficiently from the registry and can be considered more valid and stable than estimates taken from a specific (smaller) control group. In order to compute the expected numbers of a specific type of cancer, we calculated each relative's time at risk as the number of years from his/her date of birth to the date of data collection, cancer diagnosis, or death, whichever came first. We then stratified the total person-years at risk by sex and age (5-year categories). The expected numbers were obtained by multiplying the person-years at risk in each category by the age and sex-specific incidence rates for the type of cancer obtained from the NCR in 2003. Finally, the observed/expected (O/E) ratios with $95 \%$ confidence intervals (CIs) were calculated. The 95\% CIs were calculated using the Mid-P exact test.

\section{Results}

Out of 249 questionnaires, 157 (63\%) were completed and returned. After one reminder and telephone contact, 92 questionnaires could not be included in the analysis, because the patients refused to participate $(n=47)$, did not fill out the questionnaire completely $(n=19)$ or did not return the questionnaire $(n=26)$. Table 1 presents the characteristics of BCC-patients and their relatives.

The 157 BCC-patients had 1,272 first-degree relatives; 263 of them had cancer. As some relatives had more than one form of cancer, 277 malignancies were reported in total. The $\mathrm{O} / \mathrm{E}$ ratios for different forms of cancer in relatives are given in Table 2; categories are based on the NCR (http://www.ikcnet.nl). Two forms of cancer could not be classified in one of the categories (cancer of the peritoneum and a carcinoid tumour), and were excluded from the sitespecific analysis. Tumours that were described as "cancer in the belly" $(n=3)$ were classified as a tumour of the digestive tract.

Table 1 Characteristics of BCC-patients and their relatives

\begin{tabular}{lll}
\hline Characteristics & $\begin{array}{l}\text { Patients with a } \\
\text { first BCC }<51 \text { years } \\
\text { of age }(n=75)\end{array}$ & $\begin{array}{l}\text { Patients with a } \\
\text { first BCC }>50 \text { years } \\
\text { of age }(n=82)\end{array}$ \\
\hline $\begin{array}{c}\text { Mean age first } \\
\text { BCC (range) }\end{array}$ & $41.1(15-50)$ & $62.5(51-88)$ \\
$\begin{array}{c}\text { Mean number of } \\
\text { BCCs (range) }\end{array}$ & $4.7(1-42)$ & $5.1(1-150)$ \\
$\begin{array}{c}\text { Number of relatives } \\
\text { Mean age of } \\
\text { relatives (range) }\end{array}$ & 583 & 689 \\
\hline
\end{tabular}

$B C C$ basal cell carcinoma
The following cancers were statistically significant, higher than expected in relatives of young BCC-patients: bone and soft tissue, skin and digestive tract. For relatives of older BCC-patients, this only applies for cancers of the digestive tract. In relatives of both young and older BCCpatients, cancer of the male genital tract was statistically significant less observed than was expected.

Twenty-six BCC-patients refused to approach their relatives who had cancer. The remaining 98 BCC-patients had 193 relatives with cancer; 105 of them gave permission to confirm the diagnosis. As the registration of the NCR started in 1989, confirmation of the diagnosis was only possible when the relative was diagnosed as suffering from cancer after 1988. For that reason, confirmation was sought in 47 cases. The diagnosis was accurate in $41(87 \%)$ of these cases. Three relatives had more than one malignancy: skin and colon, skin and blood/lymph node and breast and female genital tract. Diagnoses that were inaccurate and the corresponding accurate diagnoses according to the NCR are shown in Table 3.

\section{Discussion}

In this study, we investigated whether BCCs are associated with the occurrence of other malignancies in the patient's family. In relatives from both young and old BCC-patients, an increased incidence of cancer of the digestive tract was observed. Remarkably, this increased incidence was strongly influenced by relatives with cancer of the liver. However, it is likely that most of these tumours are metastases instead of primary cancer. The increased $\mathrm{O} / \mathrm{E}$ ratio is thus the result of misclassification bias. The same goes for cancer of bone and soft tissue and, to a lesser extent, the central nervous system.

The incidence of cutaneous malignancies among relatives of young BCC-patients was higher than expected. This might indicate that first-degree relatives have an increased risk of skin malignancies. However, it is also possible that this high rate is due to recall bias by the patients, which led to an overestimation of skin malignancies. Furthermore, it might be possible that the incidence rates for skin cancer of the NCR are not correct; the Comprehensive Cancer Centre South (IKZ) is the only Dutch Cancer Centre that registers BCCs which implicates that the incidence of skin tumours according to the NCR might be an underestimation. Besides, the high incidence of skin malignancies among relatives of BCC-patients might be based on coincidence. An earlier pilot study confirmed the increased incidence of cutaneous malignancies among relatives of young patients with skin cancer; in this study, the incidence of cancer in first-degree relatives from patients with skin cancer under the age of 51 years ("young"), relatives from 
Table 2 Types of cancer in first-degree relatives of BCC-patients

\begin{tabular}{|c|c|c|c|c|c|c|c|c|}
\hline \multirow[t]{3}{*}{ Type of cancer } & \multicolumn{4}{|c|}{$\begin{array}{l}\text { First-degree relatives of patients with } \\
\text { a first BCC }<51 \text { years of age }(n=583)\end{array}$} & \multicolumn{4}{|c|}{$\begin{array}{l}\text { First-degree relatives of patients with } \\
\text { a first BCC }>50 \text { years of age }(n=689)\end{array}$} \\
\hline & \multirow[t]{2}{*}{ Obs } & \multicolumn{3}{|c|}{$95 \% \mathrm{CI}$} & \multirow[t]{2}{*}{ Obs } & \multicolumn{3}{|c|}{$95 \% \mathrm{CI}$} \\
\hline & & $\mathrm{O} / \mathrm{E}$ & Lower & Upper & & $\mathrm{O} / \mathrm{E}$ & Lower & Upper \\
\hline All tumours & 111 & 1.17 & 0.96 & 1.40 & 166 & 1.02 & 0.87 & 1.18 \\
\hline Blood, lymph node & 8 & 1.08 & 0.50 & 2.05 & 6 & 0.50 & 0.20 & 1.03 \\
\hline Breast & 20 & 1.25 & 0.79 & 1.90 & 28 & 1.10 & 0.75 & 1.57 \\
\hline Bone and soft tissue & 5 & 3.91 & 1.43 & 8.66 & 2 & 1.03 & 0.17 & 3.41 \\
\hline Central nervous system & 2 & 1.20 & 0.20 & 3.96 & 6 & 2.36 & 0.96 & 4.91 \\
\hline Endocrine glands & 2 & 2.90 & 0.49 & 9.58 & 2 & 1.96 & 0.33 & 6.48 \\
\hline Head and neck & 3 & 0.89 & 0.23 & 2.41 & 4 & 0.71 & 0.22 & 1.71 \\
\hline Skin & 18 & 2.13 & 1.30 & 3.29 & 18 & 1.26 & 0.77 & 1.95 \\
\hline Male genital tract & 3 & 0.29 & 0.07 & 0.78 & 9 & 0.47 & 0.23 & 0.87 \\
\hline Trachea, lung and mesothelioma & 12 & 0.96 & 0.52 & 1.64 & 25 & 1.13 & 0.75 & 1.64 \\
\hline Digestive tract & 31 & 1.59 & 1.10 & 2.23 & 50 & 1.44 & 1.08 & 1.89 \\
\hline Colorectal & 18 & 1.50 & 0.91 & 2.32 & 22 & 1.03 & 0.66 & 1.53 \\
\hline Stomach & 2 & 0.77 & 0.13 & 2.54 & 5 & 1.07 & 0.39 & 2.37 \\
\hline Liver & 4 & 9.52 & 3.03 & 22.97 & 11 & 15.28 & 8.03 & 26.55 \\
\hline Oesophagus & 1 & 0.60 & 0.03 & 2.94 & 2 & 0.68 & 0.11 & 2.24 \\
\hline Pancreas & 3 & 1.62 & 0.41 & 4.41 & 4 & 1.22 & 0.39 & 2.94 \\
\hline Urinary tract & 2 & 0.37 & 0.06 & 1.23 & 5 & 0.52 & 0.19 & 1.15 \\
\hline Female genital tract & 4 & 0.82 & 0.26 & 1.97 & 8 & 1.00 & 0.47 & 1.90 \\
\hline
\end{tabular}

$C I$ confidence interval, $O b s$ observed, $O / E$ observed/expected, $B C C$ basal cell carcinoma

Table 3 Diagnoses that were inaccurately reported by BCCpatients and the corresponding accurate diagnoses according to the NCR

\begin{tabular}{ll}
\hline Reported & NCR \\
\hline Pleura & Breast \\
Lung & Colon \\
Oesophagus & Stomach \\
Cervix & Colon \\
Breast & Colon \\
Peritoneum & Colon \\
\hline
\end{tabular}

patients with skin cancer over the age of 50 years ("old") and patients with benign skin neoplasms were compared with a control group (patients who were treated with laser therapy for vascular skin disorders). It turned out that the incidence of skin cancer in relatives of young patients with skin cancer was higher than that in both relatives of the control group and relatives of the young patients with benign neoplasms and relatives of old patients with skin cancer (unpublished data). Another theoretical explanation for the high incidence of cutaneous malignancies among relatives of young BCC-patients is surveillance bias. In reality, it seems unlikely that a BCC is a reason for increased screening or case finding of tumours of internal organs in relatives of patients. Furthermore, the cancers diagnosed among relatives are not necessarily diagnosed after the BCC diagnosis in the proband. Alternatively, we do not think that cancer diagnoses in relatives may have led to screening or case finding of BCC in the proband.

The number of relatives who suffered from cancer of the male genital tract was lower than expected in both groups. Earlier studies already reported a decreased risk of prostate cancer in skin cancer-patients. It has been hypothesised that ultraviolet radiation protects against the development of prostate cancer, by means of vitamin D3 synthesis, whereas it increases the risk of skin cancer [6]. It is unknown whether this association could be extrapolated to relatives of BCC-patients.

It might be possible that BCC-patients misreported the cancers in their relatives as the occurrence of cancer in family members was based solely on the questionnaire [2]. For example, metastasised cancers may have been reported instead of the primary tumour, leading to over reporting of, for instance, bone and liver cancer [21]. Although only a minority of the reported cancer diagnoses could be confirmed, it turned out that $87 \%$ of the cancer diagnoses in first-degree relatives were accurately reported by the BCCpatients. This fits with previous investigations which showed that family cancer histories for first-degree relatives are accurate for the most common types of cancer, especially breast and colon cancer $[15,20,28]$. Unfortu- 
nately, we got only sparsely permission to verify the forms of cancer that were most likely to be misreported, such as cancer of the liver and bone and soft tissue.

This exploratory study suggests that the incidence of cancer, and in particular, cancer of the digestive tract, in relatives of BCC-patients is significantly increased. The association between NMSC and malignancies of the digestive tract is well known; earlier studies showed that the incidence of rare sebaceous skin tumours and keratoacanthomas in Lynch syndrome patients is increased and patients with a combination of one of these skin tumours and a Lynch syndrome-related malignancy are classified as having Muir Torre syndrome [7, $10,17]$. However, little is known with respect to the association between BCCs and visceral malignancies. The increased incidence of cancer of the digestive tract in relatives of BCCpatients that was found in this study requires further investigation in order to prove a genetic predisposition to both skin and visceral cancers in these families.

Open Access This article is distributed under the terms of the Creative Commons Attribution Noncommercial License which permits any noncommercial use, distribution, and reproduction in any medium, provided the original author(s) and source are credited.

\section{References}

1. Bale AE, Yu KP (2001) The hedgehog pathway and basal cell carcinomas. Hum Mol Genet 10:757-762

2. Bensen JT, Liese AD, Rushing JT, Province M, Folsom AR, Rich SS, Higgins M (1999) Accuracy of proband reported family history: the NHLBI Family Heart Study (FHS). Genet Epidemiol 17:141-150

3. Christenson LJ, Borrowman TA, Vachon CM, Tollefson MM, Otley CC, Weaver AL, Roenigk RK (2005) Incidence of basal cell and squamous cell carcinomas in a population younger than 40 years. JAMA 294:681-690

4. Curry ML, Eng W, Lund K, Paek D, Cockerell CJ (2004) MuirTorre syndrome: role of the dermatopathologist in diagnosis. Am J Dermatopathol 26:217-221

5. de Vries E, Louwman M, Bastiaens M, de GF, Coebergh JW (2004) Rapid and continuous increases in incidence rates of basal cell carcinoma in the southeast Netherlands since 1973. J Invest Dermatol 123:634-638

6. de Vries E, Soerjomataram I, Houterman S, Louwman MW, Coebergh JW (2007) Decreased risk of prostate cancer after skin cancer diagnosis: a protective role of ultraviolet radiation? Am J Epidemiol 165:966-972

7. Fusaro RM, Lemon SJ, Lynch HT (1996) Muir-Torre syndrome and defective DNA mismatch repair genes. J Am Acad Dermatol 35:493-494

8. Happle R (2000) Nonsyndromic type of hereditary multiple basal cell carcinoma. Am J Med Genet 95:161-163

9. Holikova Z, Massi D, Lotti T, Hercogova J (2004) Insight into the pathogenesis of sporadic basal cell carcinoma. Int J Dermatol 43:865-869

10. Kruse R, Rutten A, Lamberti C, Hosseiny-Malayeri HR, Wang Y, Ruelfs C, Jungck M, Mathiak M, Ruzicka T, Hartschuh W, Bisceglia M, Friedl W, Propping P (1998) Muir-Torre phenotype has a frequency of DNA mismatch-repair-gene mutations similar to that in hereditary nonpolyposis colorectal cancer families defined by the Amsterdam criteria. Am J Hum Genet 63:63-70

11. Lear JT, Smith AG, Heagerty AH, Bowers B, Jones PW, Gilford J, Alldersea J, Strange RC, Fryer AA (1997) Truncal site and detoxifying enzyme polymorphisms significantly reduce time to presentation of further primary cutaneous basal cell carcinoma. Carcinogenesis 18:1499-1503

12. Lee DA, Grossman ME, Schneiderman P, Celebi JT (2005) Genetics of skin appendage neoplasms and related syndromes. J Med Genet 42:811-819

13. Liboutet M, Portela M, Delestaing G, Vilmer C, Dupin N, Gorin I, Saiag P, Lebbe C, Kerob D, Dubertret L, Grandchamp B, BassetSeguin N, Soufir N (2006) MC1R and PTCH gene polymorphism in French patients with basal cell carcinomas. J Invest Dermatol 126:1510-1517

14. Matta JL, Villa JL, Ramos JM, Sanchez J, Chompre G, Ruiz A, Grossman L (2003) DNA repair and nonmelanoma skin cancer in Puerto Rican populations. J Am Acad Dermatol 49:433-439

15. Murff HJ, Spigel DR, Syngal S (2004) Does this patient have a family history of cancer? An evidence-based analysis of the accuracy of family cancer history. JAMA 292:1480-1489

16. Ponti G, Losi L, Di Gregorio C, Roncucci L, Pedroni M, Scarselli A, Benatti P, Seidenari S, Pellacani G, Lembo L, Rossi G, Marino M, Lucci-Cordisco E, de Leon MP (2005) Identification of MuirTorre syndrome among patients with sebaceous tumors and keratoacanthomas: role of clinical features, microsatellite instability, and immunohistochemistry. Cancer 103:1018-1025

17. Ponti G, Losi L, Pedroni M, Lucci-Cordisco E, Di GC, Pellacani G, Seidenari S (2006) Value of MLH1 and MSH2 mutations in the appearance of Muir-Torre syndrome phenotype in HNPCC patients presenting sebaceous gland tumors or keratoacanthomas. J Invest Dermatol 126:2302-2307

18. Rosenberg CA, Greenland P, Khandekar J, Loar A, Ascensao J, Lopez AM (2004) Association of nonmelanoma skin cancer with second malignancy. Cancer 100:130-138

19. Rubin AI, Chen EH, Ratner D (2005) Basal-cell carcinoma. N Engl J Med 353:2262-2269

20. Sijmons RH, Boonstra AE, Reefhuis J, Hordijk-Hos JM, de Walle HE, Oosterwijk JC, Cornel MC (2000) Accuracy of family history of cancer: clinical genetic implications. Eur J Hum Genet 8:181-186

21. Spermon JR, Witjes JA, Nap M, Kiemeney LA (2001) Cancer incidence in relatives of patients with testicular cancer in the eastern part of The Netherlands. Urology 57:747-752

22. Tilli CM, Van Steensel MA, Krekels GA, Neumann HA, Ramaekers FC (2005) Molecular aetiology and pathogenesis of basal cell carcinoma. Br J Dermatol 152:1108-1124

23. Troyanova P, Danon S, Ivanova T (2002) Nonmelanoma skin cancers and risk of subsequent malignancies: a cancer registry-based study in Bulgaria. Neoplasma 49:81-85

24. Tsao H (2000) Update on familial cancer syndromes and the skin. J Am Acad Dermatol 42:939-969

25. Umar A, Boland CR, Terdiman JP, Syngal S, de la CA, Ruschoff J, Fishel R, Lindor NM, Burgart LJ, Hamelin R, Hamilton SR, Hiatt RA, Jass J, Lindblom A, Lynch HT, Peltomaki P, Ramsey SD, Rodriguez-Bigas MA, Vasen HF, Hawk ET, Barrett JC, Freedman AN, Srivastava S (2004) Revised Bethesda Guidelines for hereditary nonpolyposis colorectal cancer (Lynch syndrome) and microsatellite instability. J Natl Cancer Inst 96:261-268

26. Wallberg P, Kaaman T, Lindberg M (1998) Multiple basal cell carcinoma. A clinical evaluation of risk factors. Acta Derm Venereol 78:127-129

27. Wassberg C, Thorn M, Yuen J, Ringborg U, Hakulinen T (1996) Second primary cancers in patients with cutaneous malignant melanoma: a population-based study in Sweden. Br J Cancer 73:255-259

28. Ziogas A, Anton-Culver H (2003) Validation of family history data in cancer family registries. Am J Prev Med 24:190-198 